\title{
NDVI as a Tool for Analysing Changes in Coconut Growing Areas of Coimbatore District of Tamil Nadu, India
}

\author{
Balaji Kannan $^{1^{*}}$, R. Kumaraperumal ${ }^{2}$, K. P. Ragunath ${ }^{2}$ and R. Jagadeeswaran ${ }^{3}$ \\ ${ }^{1}$ Department of Soil and Water Conservation Engineering, Agricultural Engineering College \\ and Research Institute, Tamil Nadu Agricultural University, Coimbatore - 641 003, India \\ ${ }^{2}$ Department of Remote Sensing and GIS, Tamil Nadu Agricultural University, \\ Coimbatore, India \\ ${ }^{3}$ (SS\&AC), Agricultural College and Research Institute, (Tamil Nadu Agricultural University), \\ Kudumiyanmalai, India \\ *Corresponding author
}

\section{A B S T R A C T}

Keywords

LISS III, Landsat 8, NDVI, Coconut

Article Info

Accepted:

22 March 2020

Available Online:

10 April 2020
Discrimination and Interpretation of various land cover and land resources can be done using estimation of Normalized Difference Vegetation Index (NDVI) from multi spectral satellite data. This study has been attempted to analyse the changes is coconut growing areas of Coimbatore District in Tamil Nadu using multi temporal images of LISS III and Landsat 8 during 2012 and 2015 respectively Cross tabulation of the two temporal NDVI images were done and it could be observed that around $50 \%$ of the total area remains in active plantation. It is also inferred that, in 1118 ha there is a reduction in NDVI value, which means the presence of unhealthy crop or total reduction in number of coconut trees in these areas. Similarly, in 32653 ha there is an increase in NDVI value which indicates in healthier crop or newer establishment of crop.

\section{Introduction}

Multi-temporal satellite data has been used for a plethora of studies throughout the world. One major area of using multi temporal remote sensed images is change detection analysis of cropped area. Normalized differential vegetation index (NDVI) has evolved as universal tool for studying the vegetation status in a cropped land. NDVI is also the most widely used tool for vegetation related studies (Xue and $\mathrm{Su}, 2017$ ).

There has been a lot of studies with regard to increasing use of the Normalized Difference Vegetation Index (NDVI) in ecological studies (Nathalie Pettorelli, 2005). This study is done by integrating both the use of multi 
temporal images and NDVI for analysing the changes in coconut growing areas of Coimbatore District in Tamil Nadu.

\section{Materials and Methods}

Coimbatore District is a district in the Indian state of Tamil Nadu. Coimbatore is the administrative headquarters of the district. Coimbatore lies between $10^{\circ} 13.21^{\prime}$ to $11^{\circ} 24.39^{\prime} \mathrm{N}$ latitude and $76^{\circ} 39.34^{\prime}$ to $77^{\circ} 23.23^{\prime}$ E longitude.

\section{Satellite data}

LISS 3 and Landsat 8 satellite images were used in this study. The description of the data sources is described in detail (Table 1).

\section{Materials and Methods}

The methodology as explained in the flowchart through Fig.1 is followed in this study. Satellite data has been downloaded for two different time periods (2012 and 2015). Normalized difference vegetation index images were derived for both time periods. An existing coconut growing area shape file of Coimbatore district is used as a mask for extracting NDVI values for those areas only. Cross-tabulation of resultant NDVI images were done (Fig. 2).

NDVI is an index which enhances vegetation pixels by showing the difference between near-infrared reflectance (which is strongly reflected by vegetation) and red reflectance (which is absorbed by vegetation). NDVI is computed by the following formula (Equation 1),

$\mathrm{NDVI}=\frac{\mathrm{NIR}-\mathrm{R}}{\mathrm{NIR}+\mathrm{R}}$

Source: Zhang et al., (2011)
Where, NIR stands for the reflectance in the Near Infrared Band

$\mathrm{R}$ stands for the reflectance in the Red Band

In LISS 3, Band 4 and Band 3 are used for NIR and RED respectively and in Landsat 8 image, Band 5 and Band 4 were used for NIR and RED respectively.

The NDVI values for the coconut growing areas of Coimbatore were extracted. Normalised Difference Vegetation Index gives a fair estimate on the health and greenery of the vegetation. A value of NDVI is greater than 0.5 , indicates better health of vegetation. A value of NDVI between 0.2 to 0.5 indicates dry vegetation or replacement of vegetation with other land use / cover and value of less than 0.2 indicates land use classes other than vegetation. Based on this background, the NDVI images were classified. Finally, cross tabulation of the reclassified NDVI images were done for analysing the changes that occurred in the coconut growing areas of the Coimbatore district, Tamil Nadu, India.

\section{Results and Discussion}

The NDVI images for the coconut growing areas of Coimbatore district for the year 2012 and 2015 are presented through Figure 3 and Figure 4 respectively. It was observed that the NDVI values predominantly range from greater than zero to 0.6. For observing the changes in the coconut growing areas the NDVI values are reclassified as less than 0.2 as $1,0.2$ to 0.5 as 2 and greater than 0.5 as 3 .

Cross tabulation of the two temporal NDVI images was done and the result is shown in the Table 2 (area in hectares). It could be observed that around $50 \%$ of the total area remains in active plantation. 
Table.1 Satellite data used for the study

\begin{tabular}{|l|l|l|l|l|l|}
\hline \multicolumn{1}{|c|}{ Sensor } & Year & Path /Row & $\begin{array}{c}\text { Date of } \\
\text { Acquisition }\end{array}$ & $\begin{array}{c}\text { Spectral Bands and } \\
\text { their wavelengths } \\
(\mu \mathrm{m}) \text { used for this } \\
\text { study }\end{array}$ & $\begin{array}{c}\text { Spatial } \\
\text { Resolution } \\
(\mathrm{m})\end{array}$ \\
\hline LISS 3 & 2012 & $\begin{array}{l}100 / 65 \\
100 / 66\end{array}$ & 20th March & $\begin{array}{l}\text { Band 3 }-0.62-0.68 \\
\text { Band } 4-0.77-0.86\end{array}$ & 23.5 \\
\hline LANDSAT 8 & 2015 & $\begin{array}{l}144 / 52 \\
144 / 53\end{array}$ & 19th March & $\begin{array}{l}\text { Band } 4-0.64-0.67 \\
\text { Band 5 - 0.85 - } 0.88\end{array}$ & 30.0 \\
\hline
\end{tabular}

Table.2 Cross tabulation of NDVI classes of 2012 and 2015

\begin{tabular}{|c|c|c|c|c|}
\hline \multicolumn{3}{|c|}{} & \multicolumn{4}{|c|}{2015} \\
\hline \multirow{3}{*}{$\sqrt{*}$} & & 1 & 2 & 3 \\
\cline { 2 - 5 } & 1 & 4177 & 32653 & 3 \\
\cline { 2 - 5 } & 2 & 1118 & 46668 & 4 \\
\cline { 2 - 5 } & 3 & 0.18 & 2.34 & 0 \\
\hline
\end{tabular}

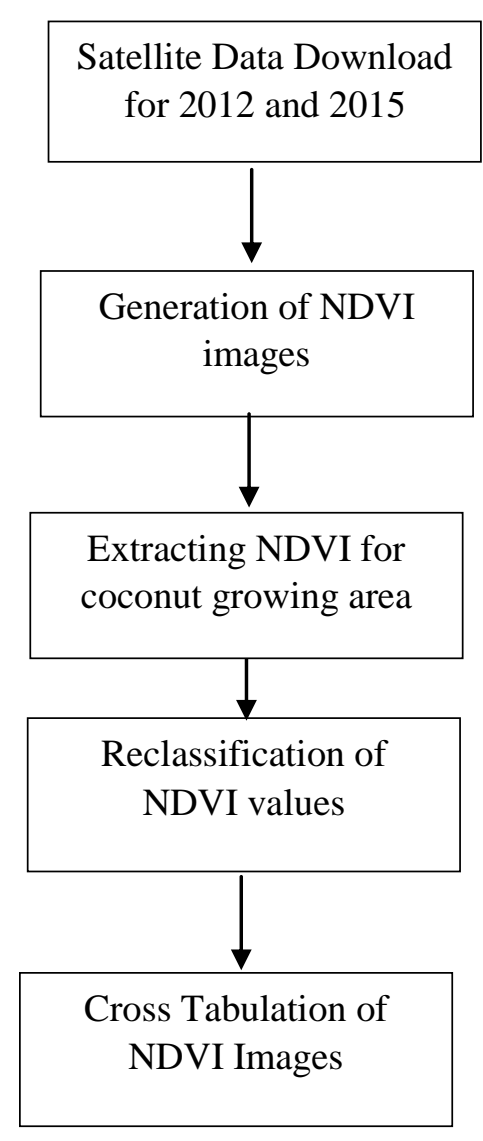

Fig.1 Methodology 
Int.J.Curr.Microbiol.App.Sci (2020) 9(4): 2935-2939

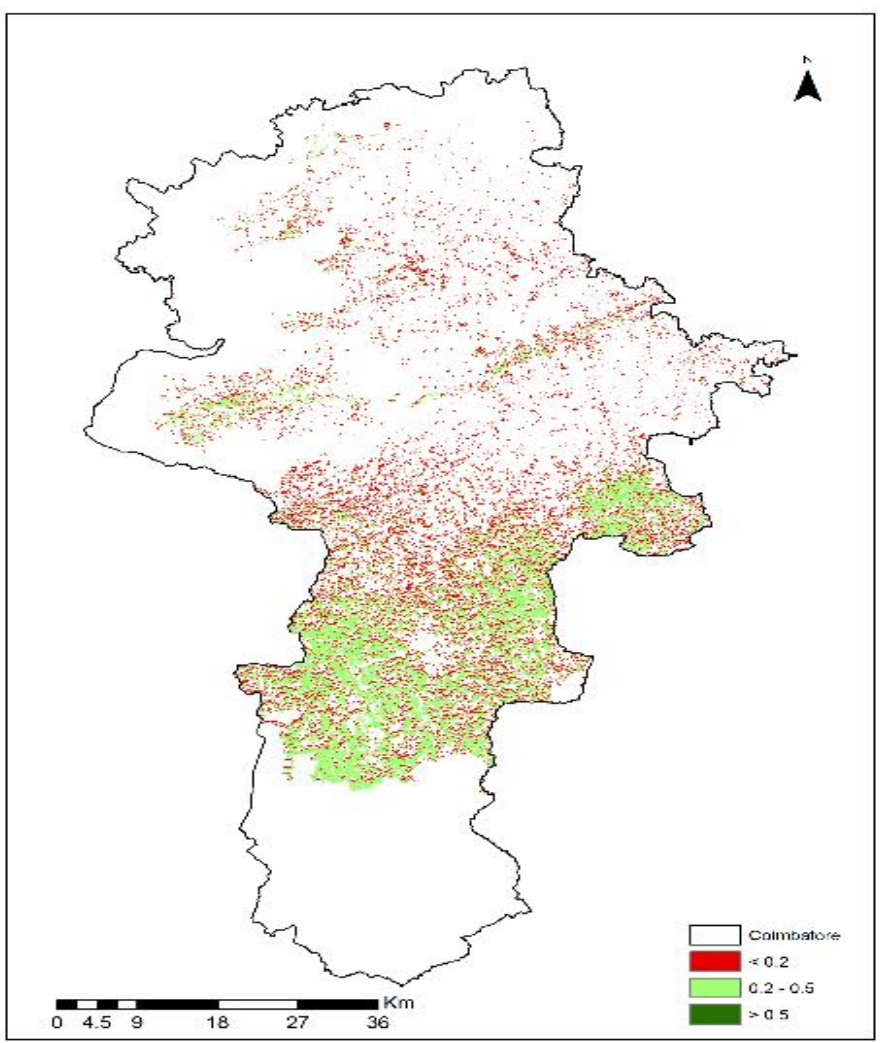

Fig.2 NDVI Image of Coimbatore district in 2012

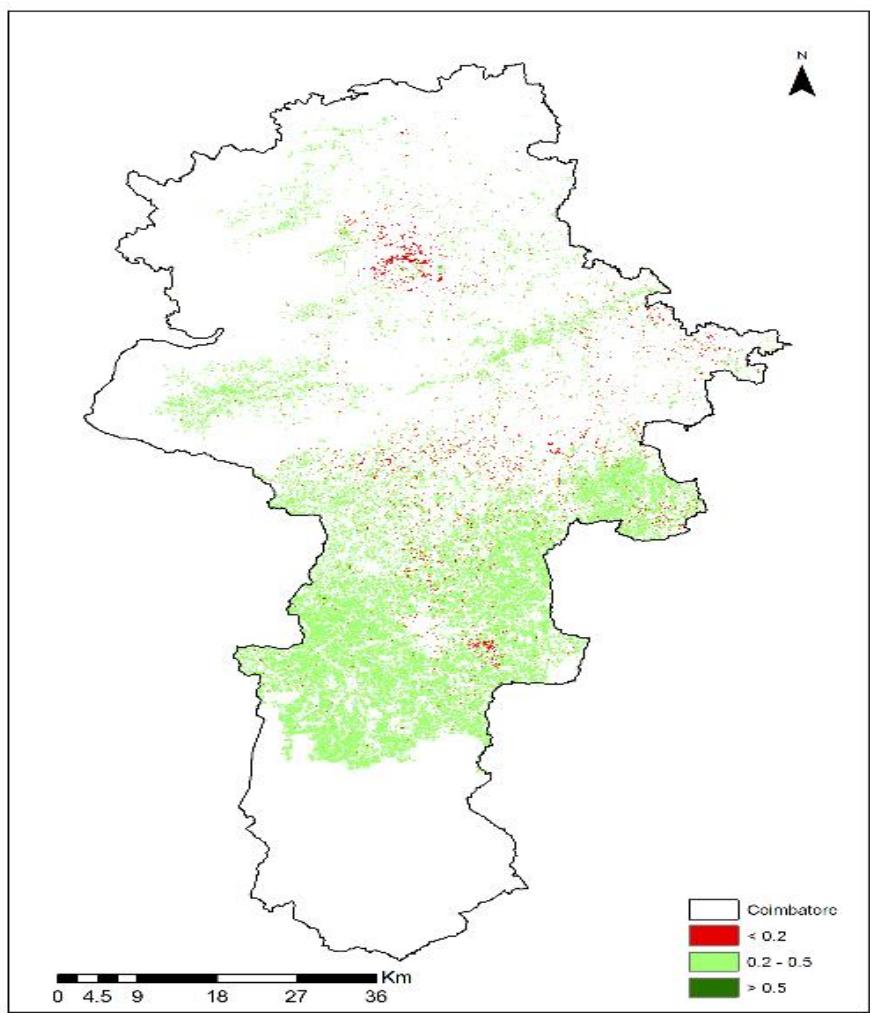

Fig.3 NDVI Image of Coimbatore district in 2015 
It is also inferred that, in 1118 ha there is a class change from 2 to 1 , which indicates reduction in NDVI value, which means the presence of unhealthy crop or total reduction in number of coconut trees in these areas. Similarly, in 32653 ha there is class change from 1 to 2 , which indicates in healthier crop or newer establishment of crop. Hence, the use of tools like NDVI using remote sensing imageries can be considered as a easier substitute rather than collecting field data which becomes difficult at a regional scale. Turner et al., (2003) has also expressed a similar view through their studies.

From this study, it can be deduced that Normalized Difference Vegetation Index can be utilised as tool for change detection in vegetated areas.

\section{References}

Nathalie Pettorelli, Jon Olav Vik,
AtleMysterud, Jean-Michel Gaillard, Compton J. Tucker and Nils Chr. Stenseth 2005. Using the satellitederived NDVI to assess ecological responses to environmental change. Trends in Ecology and Evolution, Vol.20 No.9 September 2005.

Turner, W. Spector, S., Gardiner, N, and Fladeland, M. 2003. Remote sensing for biodiversity science and conservation. Trends Ecol. Evol. 18, 306-314

Xue, J. and Su, B. 2017. Significant remote sensing vegetation indices: areview of developments and applications. J Sens, 2017

Zhang, N., Zhu L. and Zhu, Y. 2011. Urban heat island and boundary layer structures under hot weather synoptic conditions: A case study of Suzhou City, China. Advances in Atmospheric Sciences, 28, pp. 855-865.

\section{How to cite this article:}

Balaji Kannan, R. Kumaraperumal, K. P. Ragunath and Jagadeeswaran, R. 2020. NDVI as a Tool for Analysing Changes in Coconut Growing Areas of Coimbatore District of Tamil Nadu, India. Int.J.Curr.Microbiol.App.Sci. 9(04): 2935-2939.

doi: https://doi.org/10.20546/ijcmas.2020.904.343 